\title{
Hip Spacers in Two-Stage Revision for Periprosthetic Joint Infection: A Review of Literature
}

\author{
Alessandro Rava1® Matteo Bruzzone ${ }^{2}$ Umberto Cottino ${ }^{2}$ Emilio Enrietti ${ }^{1}$ Roberto Rossi ${ }^{2}$ \\ 1 Scuola di Specializzazione in Ortopedia e Traumatologia, Università \\ degli Studi di Torino, Torino, Italy \\ 2 SC Ortopedia e Traumatologia, AO Ospedale Mauriziano Umberto I, \\ Torino, Italy \\ Address for correspondence Alessandro Rava, MD, Scuola di \\ Specializzazione in Ortopedia e Traumatologia, Università degli Studi \\ di Torino, Via Zuretti 29, 10131 Torino, Italy \\ (e-mail: dralessandrorava@gmail.com).
}

Joints 2019;7:56-63.

\author{
Abstract \\ Keywords \\ - antibiotic \\ - hip \\ - infection \\ - periprosthetic joint \\ infections \\ - antibiotic-loaded \\ spacers
}

Infection after total hip arthroplasty (THA) is a devastating complication with significant consequences for patients. In literature, single and two-stage revision, irrigation and debridement, Girdlestone resection arthroplasty, and arthrodesis and amputation are reported as possible treatments. Recently, two-stage revision has become popular as the gold standard treatment for chronic hip joint infections after THA. In this review, we evaluate the current literature about microbiology of periprosthetic joint infections and the use of antibiotic-loaded cement spacers. We aim to give an overview about indications, clinical results, and mechanical complications for spacers implantation, evaluating also selection criteria, pharmacokinetic properties, and systemic safety of the most frequently used antibiotics.

\section{Introduction}

Infection is a devastating, costly, and challenging complication following total hip arthroplasty (THA), with an incidence of 1 to $2 \%$ and 3 to $4 \%$ in primary and revision cases, respectively. ${ }^{1-4}$

It's very important for every orthopedic surgeon to know how to recognize and consequently to treat this complication.

In 2011, the Musculoskeletal Infection Society and the Center for Disease Control convened a work group to formulate a definition for periprosthetic joint infection (PJI). ${ }^{5}$

They defined that PJI can be diagnosed if one of these major criteria is present:

- Presence of a sinus tract communicating with the prosthesis.

- Isolation of a pathogen via culture from two separated tissues or fluid samples or if four or more of the minor criteria are present:

- Raised erythrocyte sedimentation rate (ESR).

- Elevated synovial white blood cell count.

- Elevated synovial polymorphonuclear leukocytes (PMN) percentage.

- Purulent fluid in the affected joint.

\begin{abstract}
- A pathogen isolated from one specimen of periprosthetic tissue or fluid.

- More than five PMNs per high power field microscopy in five high power fields.
\end{abstract}

Infections can be divided in acute ( $<4$ weeks) and chronic ( $>4$ weeks). Chronic infections are more frequent, and twostage revision is considered gold standard. ${ }^{6}$ In literature, also single-stage revision and irrigation and debridement are reported as valid treatments; while Girdlestone resection arthroplasty, arthrodesis, and amputation are nowadays only rescue procedures to be considered in few selected patients.

\section{Microbiology: Which Bacteria Affect the THA?}

Different bacteria are involved in PJI. To treat the infection, it is important to recognize the pathogen agent. PJI typically occurs as a result of bacteria inoculation during surgery, contiguous spread of infection from an adjacent site, or hematogenous seeding secondary to an infection located received

March 18, 2018

accepted

August 6, 2019

published online

October 11, 2019
DOI https://doi.org/

10.1055/s-0039-1697608. ISSN 2282-4324.
Copyright $\odot 2019$ Georg Thieme Verlag License terms

KG Stuttgart · New York

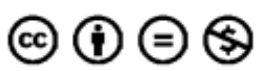


far away from the hip. Obviously, infection prevention is fundamental. Illingworth et $\mathrm{al}^{7}$ have recently defined a correct pre and postoperative management. They underlined the importance of Staphylococcus aureus as pathogen agent. This gram-positive bacterium had a prevalence of colonization of $32.4 \%$ in 2001 to 2004: this percentage decreased to $28.6 \%$ thanks to decolonization protocols that include combinations of mupirocin nasal ointment application, chlorhexidine mouth rinse, and chlorhexidine body wash for up to 5 days preceding surgery. Staphylococcus is for sure the most frequent bacteria causing a PJI, due to its intrinsic capability to adhere to biofilm and to solid matrix.

Biofilm is made of polysaccharides, proteins, and extracellular DNA. It protects bacteria by antimicrobial drugs and host immune system making infection treatment very difficult. ${ }^{8}$

The low drugs susceptibility of bacteria covered by biofilm is derived by a low growth rate and presence of resistant bacterial subpopulations. ${ }^{9}$ Furthermore, the presence of biofilm causes delays in diagnosis limiting culture's sensitivity.

Between the most frequent etiological agents (in addition to $S$. aureus) we have to consider the negative coagulase staphylococci, especially the Staphylococcus epidermidis. ${ }^{10}$ This agent has a high virulence due to its capability to adhere to prosthetic material.

Analyzing some studies, published in the past 5 years and extrapolating the epidemiological data reported in - Table 1, ${ }^{11-18}$ we noticed how the incidence of Staphylococcus infection is the most frequent attending for almost $70 \%$ of the cases. Similar results are reported by Tande and Patel that reviewed 14 studies with a total of 2,400 patients. ${ }^{19}$ Strepto- coccus are less involved, even if Streptococcus agalactiae has to be mentioned. Streptococcus is a gram-positive bacteria characterized by the presence of wall antigens $B$. It is often present in the infection of the urogenital apparatus in women, and its involvement in PJI is a negative prognostic factor. ${ }^{20}$

\section{Two-Stage Revision Surgical Technique}

As mentioned before, it is the gold standard treatment for PJI. It is divided into two different stages.

The first one consists of the prosthesis removal, sample collection for histology/microbiology and spacer placement; meanwhile the second one consists of spacer and cement removal, sample collection for histology/microbiology, and new implant selection and placement.

During the first stage, the joint exposure should be performed on the original incision.

Accurate debridement of fibrous and necrotic tissue is mandatory.

Antibiotics prophylaxis should not be started until three to six microbiological samples are taken. ${ }^{20,21}$ Then the prosthetic components have to be removed taking attention to avoid any damage to the bone, which could be fragile. While removing the acetabular component the surgeon should pay attention to avoid the creation of segmental defects on the acetabular rim that can potentially determine subsequent spacer instability. Removal of the prosthetic stem can be complex, especially if cemented fixation was used. A complete series of blades and chisels must be available in the operating room.

Table 1 Epidemiological data reported in literature

\begin{tabular}{|l|l|l|l|l|l|l|l|l|l|}
\hline & MSSA & MRSA & $\begin{array}{l}\text { Staphylo- } \\
\text { coccus } \\
\text { aureus }\end{array}$ & $\begin{array}{l}\text { Coagulase- } \\
\text { negative } \\
\text { Staphylococcus }\end{array}$ & $\begin{array}{l}\text { Strepto- } \\
\text { coccus }\end{array}$ & $\begin{array}{l}\text { Coryne- } \\
\text { bacterium }\end{array}$ & $\begin{array}{l}\text { Entero- } \\
\text { coccus }\end{array}$ & $\begin{array}{l}\text { Gram } \\
\text { negative }\end{array}$ & Polymicrobial \\
\hline $\begin{array}{l}\text { Grammatopoulos } \\
\text { et al (2017) }\end{array}$ & - & - & 26 & 16 & 8 & - & - & 10 & 21 \\
\hline $\begin{array}{l}\text { Marczak et al } \\
\text { (2017) }\end{array}$ & 34 & 12 & - & 11 & 7 & - & 4 & - & - \\
\hline $\begin{array}{l}\text { Beaupre et al } \\
\text { (2017) }\end{array}$ & - & - & 5 & 11 & - & - & - & - & - \\
\hline $\begin{array}{l}\text { Anagnostakos } \\
\text { et al (2016) }\end{array}$ & - & - & - & - & - & - & - & - & - \\
\hline $\begin{array}{l}\text { Lee et al } \\
\text { (2017) }\end{array}$ & 10 & 13 & - & 7 & 4 & 1 & 1 & - & 3 \\
\hline $\begin{array}{l}\text { Gomez et al } \\
\text { (2015) }\end{array}$ & 30 & - & - & 24 & 9 & - & 4 & 10 & 15 \\
\hline $\begin{array}{l}\text { Ben Lulu et al } \\
\text { (2012) }\end{array}$ & - & - & 2 & 3 & 1 & - & 2 & 1 & - \\
\hline $\begin{array}{l}\text { Romanò et al } \\
\text { (2012) }\end{array}$ & 23 & 15 & - & 29 & - & - & 3 & 12 & - \\
\hline Total (375) & 97 & 40 & 33 & 99 & 29 & 1 & 14 & 23 & 39 \\
\hline Total \% & 25.87 & 10.7 & 8.8 & 26.4 & 7.7 & 0.27 & 3.73 & 6.13 & 10.4 \\
\hline $\begin{array}{l}\text { Tot\% } \\
\text { Staphylococcus }\end{array}$ & 71.77 & & & & & & & & \\
\hline
\end{tabular}

Abbreviations: MRSA, Methicillin-resistant Staphylococcus aureus; MSSA, Methicillin-sensitive Staphylococcus aureus. 
When a stem is well fixed, transferal osteotomy or extended trochanteric osteotomy may be needed to remove the stem. Unfortunately, these procedures have high complication rate. $^{22,23}$

Recently Chen et $\mathrm{al}^{24}$ considered the potential serious damages that the surgeon can cause by removing a well-fixed component. Due to this reason, they have assessed the possibility of partially removing previous components. In this study, the well-secured prosthetic components were retained from 16 patients. At the end of a 5-year follow-up, $81.3 \%$ of the patients were free of infection.

All removed components can undergo sonication, but in the literature, there are conflicting opinions about its efficacy. ${ }^{20}$

The next phase consists of proceeding with the placement of the antibiotic-loaded spacer that can be handmade, molded, or prefabricated. The antibiotics to be mixed with cement should be chosen based on the exams held by the surgeon such as microbiological analysis of articular fluid obtained during hospitalization. Once the spacer has been fixed, a careful hemostasis must be performed and a drainage should be positioned to avoid postoperative hematomas.

During postoperative time, it is extremely important that the patient is followed by a multispecialist team. The patient must be educated and trained to maintain a proper partial load and retrieving the mobilization or dislocation of the device. ${ }^{25}$

An adequate antibiotic therapy should be indicated by an infectious disease specialist and should be continued for approximately 6 weeks. ${ }^{5,20}$ At the end of the antibiotic therapy, patient is left antibiotics-free for about 2 weeks, and then is re-evaluated. A multispecialist consensus is needed to proceed to the second stage.

In the second stage we consider different steps: approach (made to the joint through the previous surgical scar), spacer and cement removal, sample collection for histology/microbiology, and new implant selection and placement.

The removal of spacer and cement will likely cause an additional loss of bone stock that have to be minimized. After copious pulsating washes, to remove any residual piece of cement that can be a source of reinfection, the optimum implant (that can be cemented or uncemented) is selected. The optimum management of bone loss, prosthetic design, and fixation must be preoperatively planned to achieve a stable implant.

\section{Antibiotic-Loaded Bone Cement}

Two-stage revision has two main targets: preserving soft tissue balancing (this is made possible thanks to the spacer) and defeat infection, delivering high local antibiotic dose.

The second one is achieved by the use of antibiotic-loaded bone cement (ALBC) with the help of systemic administration.

Nowadays cement can be blended with a manual mixing procedure or can be premixed in during the production of powder. Unfortunately, not every antibiotic is usable.

Anagnostakos and $\mathrm{Kelm}^{26}$ have defined some desirable characteristics like: availability in powder form, wide antibacterial spectrum, bactericidal at low concentrations, elution from polymethylmethacrylate (PMMA) in high concentrations for prolonged periods, thermal stability, low or no risk of allergy or delayed hypersensitivity, low influence on the mechanical properties of the cement, and low serum protein binding.

The same authors underlined that aminoglycosides and glycopeptides are the two groups of antibiotics that fulfill most of these criteria. Gentamicin and vancomycin are very popular in combination thanks to the availability of premixed gentamicin ALBCs and to the antistaphylococcal activity and thermal stability of vancomycin. ${ }^{27}$ Dose of antibiotic and way of preparation can affect cement mechanical properties.

First of all, we have to differ between prophylaxis, that requires low doses of antibiotic(s) (usually $\leq 1 \mathrm{~g}$ antibiotic(s)/ $40 \mathrm{~g}$ PMMA), and treatment of musculoskeletal infections, that requires higher doses (usually $4 \mathrm{~g}$ antibiotics/40 $\mathrm{g}$ PMMA). ${ }^{26}$

Unfortunately, the addition of high doses of gentamicin powder ( $>4 \mathrm{~g}$ antibiotics/40 $\mathrm{g}$ PMMA) decreases the compressive strength of the cement. The same effect can be obtained by mixing liquid antibiotics (for example in hand mixing preparations ). ${ }^{28}$ It is demonstrated that increasing dose of gentamicin in bone cement reduces shear stress strength, predisposing the cement to crack nucleation in case of prolonged dynamic loading. ${ }^{29}$ Similar loosening of mechanical strength can be obtained mixing liquid gentamycin. ${ }^{30}$

It is easy to imagine how such a large variability of options can modify mechanical properties in many different ways. The mixing method affects homogeneity of the microscopic particles and has to be considered. ${ }^{31,32}$ It is reasonable to think that the premixed cements have a greater homogeneity due to the industrial process even though some studies report a similar homogeneity between the premixed products compared with the hand mixed ones. ${ }^{33}$

Recent studies in the literature analyzed mechanical resistance to fatigue of antibiotics-loaded cements hand mixed versus premixed ones. DeLuise and $\mathrm{Scott}^{34}$ have compared a hand-mixing generic tobramycin (Pharma-Tek, Huntington, New York, United States) into Simplex P against commercially prepared tobramycin-loaded bone cement (Simplex with Tobramycin; Stryker Orthopaedics). They came to the results that the hand mixing cement suffered a $36 \%$ decrease. These findings differ with those of previous studies.

Like what happens for strength properties, even elution is influenced by the type of antibiotic, composition, mixing method, etc.

It is very important, to have a complete eradication, that the spacer releases antibiotic constantly above the minimal inhibitory concentrations (MICs) of the causative organism (s) until the prosthesis reimplantation.

Masri et al $^{35}$ measured the intra-articular antibiotic concentrations during postsurgery days. At day 1, tobramycin and vancomycin concentrations were $107 \mu \mathrm{g} / \mathrm{mL}$ and $19 \mu \mathrm{g} /$ $\mathrm{mL}$, respectively. These concentrations were 10 to 30 times higher than the MICs of the infecting organisms. The same authors found that increasing tobramycin dose may enhance both antibiotics elution but for vancomycin the increment was not the same. 
Hsieh et $\mathrm{al}^{36}$ reported on the elution of vancomycin and aztreonam. In this study, the vancomycin peak concentrations were initially $1,538 \mu \mathrm{g} / \mathrm{mL}$ and fell after 7 days to a mean value of $519 \mu \mathrm{g} / \mathrm{mL}$.

Anagnostakos et $\mathrm{al}^{37}$ determined the elution of gentamicin and vancomycin collected from the drainage fluid during a twostage protocol. They found a peak concentration for gentamicin derived from spacers of $21.15 \mu \mathrm{g} / \mathrm{mL}$, and $37.0 \mu \mathrm{g} / \mathrm{mL}$ for vancomycin on day 1. At last determination, the concentrations were respectively $1.85 \mu \mathrm{g} / \mathrm{mL}$ for gentamicin and $6.60 \mu \mathrm{g} / \mathrm{mL}$ for vancomycin after 7 days.

Boelch et $\mathrm{al}^{38}$ measured gentamicin and vancomycin concentrations derived by different antibiotic-loaded cements for 6 weeks. They analyzed PALACOS R (Heraeus. Hanau, Germany) (antibiotic free), PALACOS R $+\mathrm{G}$ (Heraeus. Hanau, Germany), COPAL G + V (Heraeus. Hanau, Germany), and COPAL $\mathrm{G}+\mathrm{C}$ (Heraeus. Hanau, Germany). They use PALACOS $\mathrm{R}$ (Pal) as control group. The test groups were PALACOS $R+G$ with premixed gentamicin (PalG), COPAL $\mathrm{G}+\mathrm{V}$ with premixed gentamicin + vancomycin (CopV), PALACOS $R+G$ manually blended with vancomycin (PalV), and COPAL $\mathrm{G}+\mathrm{C}$ containing premixed gentamicin + clindamycin $(\mathrm{CopC})$. The last one resulted to have significantly higher gentamicin concentrations than all the other formulations while for vancomycin antibiotic-loaded cements, after 12 hours, PalV produced significantly higher concentrations than premixed one. The authors affirmed that the elution from premixed gentamicin is independent of the loading technique with vancomycin while manual blending with vancomycin leads to a higher vancomycin elution at the expense of compressive strength properties. ${ }^{38}$

Similar findings are exposed by Anagnostakos and Meyer $^{39}$ in a recent systematic review. Authors underlined that antibiotics in powder form have a lower impact on the mechanical properties of bone cement whereas antibiotics in liquid form improve pharmacokinetic properties, but they have negative impact on the mechanical stability reducing the compressive strength of bone cement by $49 \%$ and the tensile strength by $46 \%$. The authors also suggest to prevent the weight bearing on the operated leg until the prosthesis reimplantation if liquid antibiotics are used.

A recent consensus defined that the best antibiotic must to be tailored for each patient based on the organism profile and patient's comorbidities. However, most infections can be treated with a spacer with vancomycin ( $1-4 \mathrm{~g}$ per $40 \mathrm{~g}$ package of cement) associated with gentamicin or tobramycin (2.4$4.8 \mathrm{~g}$ per $40 \mathrm{~g}$ package of cement). ${ }^{40}$

Despite the effort of several authors, which antibiotic is better to choose for treatment and which ALBC is mechanically superior remain unanswered questions and require additional studies. ${ }^{28}$

Antibiotic-loaded spacers can locally deliver high antibiotic concentrations that may exceed the systemic administration and for this reason can cause systemic toxicity and allergic reactions. Cases of acute renal failure, hepatic failure, bone marrow depression caused by ALBC are described in literature. ${ }^{41-43}$ Exceptionally Wentworth et $\mathrm{al}^{44}$ reported one case of dermatologic reaction in 135 hip spacer implan- tation group. The pathogenesis is not well known, it is advisable for surgeon to monitor possible skin reactions and laboratory parameters during hospital stay.

\section{Spacers}

The spacer system is an important step in the two-stage revision technique.

Its purpose is to maintain the tension of soft tissues, guarantee the continuous local release of antibiotics, and reduce hematoma formation.

Spacers are classified into two major categories: static or dynamic. Dynamic ones allow an earlier mobilization and, with regard to the hip joint, they are the majority. They can also be classified according to the manufacturing method in hand made, molded, and prefabricated. Handmade spacers have the peculiarity of being able to adapt to different needs which the surgeon may encounter during surgery. They are usually reinforced with Steinman's pins to guarantee greater resistance.

However, the most used are certainly molded and prefabricated.

Molded spacers are built directly in the operating room with the aid of a special mold in which the antibiotic cement selected is cast; they can be reinforced with hip stents or Steinman's pin that are embedded in the mold before the cement is poured. According to Faschingbauer et $\mathrm{al}^{45}$ the use of Steinman's wires reduces from 50 to $13 \%$ of the rate of mechanical complications, hypothesis confirmed by Jung et $\mathrm{al}^{25}$ who assert that the insertion of a metallic endoskeleton into antibiotic cement is a protective factor against breakage of spacer.

Ben-Lulu et $\mathrm{al}^{17}$ have described a singular spacer, after extended trochanteric osteotomy, constituted by a molded antibiotic-loaded spacer reinforced by metal endoskeleton assembled and press mounted in a precut reamed intramedullary nail filled with ALBC to bypass the distal end of osteotomy.

Prefabricated spacers are premade by industry and are available in different sizes. They have a load-bearing structure in stainless steel coated with antibiotic bone cement and resemble a femoral prosthesis. These characteristics are really appreciated by surgeons.

These spacers allow a good articulation and load in the postoperative but, as being temporary solutions they have the disadvantage of being available in limited sizes that do not always fit the patient's characteristics.

After surgery patients are usually allowed partial weightbearing with crutches. It is advisable that physiotherapist takes patients in charge from the first postoperative day. ${ }^{25}$ Usually after spacer implantation a tailored antibiotic therapy must be settled up by an infectious disease specialist. This therapy must consider intraoperative cultures results and have to be continued for a long time, approximately 4 to 6 weeks. The decision to proceed with the second stage is determined by negative cultures of a hip aspirate performed 4 weeks after discontinuation of the antibiotics and reduction of inflammatory markers (ESR $<30 \mathrm{~mm} / \mathrm{h}$ and $\mathrm{CR} p<10 \mathrm{mg} / \mathrm{L}$ ). ${ }^{46}$

We reviewed 14 articles found in literature ${ }^{12-18,47-53}$ published in the past 10 years for a total of 7,912 patients. Data are collected and reported in -Table 2. 


\begin{tabular}{|c|c|c|c|c|c|c|c|c|c|c|c|c|c|c|}
\hline 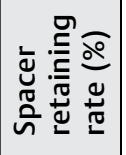 & 0 & 0 & $\stackrel{\infty}{0}$ & $\mid \begin{array}{l}\infty \\
\varphi \\
\stackrel{0}{0}\end{array}$ & $\stackrel{m}{\stackrel{m}{\sim}}$ & 0 & 守 & $\begin{array}{l}\dot{\varphi} \\
\dot{\sim}\end{array}$ & $\begin{array}{l}\underline{\Sigma} \\
\stackrel{m}{=}\end{array}$ & 1 & 0 & 0 & $\stackrel{\sim}{N}$ & 1 \\
\hline 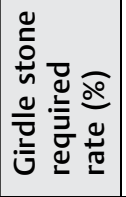 & 0 & 0 & $\begin{array}{l}\infty \\
\dot{\omega}\end{array}$ & $\hat{\text { nे }}$ & 1 & 0 & $\underset{\sim}{\mathscr{\sigma}}$ & 0 & 0 & 1 & $\stackrel{m}{m}$ & 0 & 1 & 1 \\
\hline 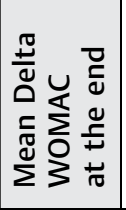 & 1 & 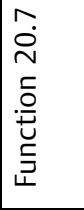 & 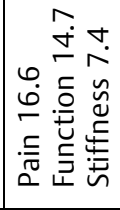 & 1 & 1 & 1 & 1 & 1 & 1 & 1 & 1 & 1 & 1 & 1 \\
\hline ؟ั̃ & $\bar{m}$ & 1 & 1 & 1 & 1 & 1 & 1 & 1 & 1 & 1 & 1 & 1 & 1 & 1 \\
\hline 呈 & 1 & $\begin{array}{l}\sim \\
\infty \\
\infty\end{array}$ & 1 & 1 & 1 & $\underset{\tilde{b}}{\stackrel{N}{*}}$ & 1 & 1 & 1 & $\stackrel{\sim}{r}$ & $\bar{\gamma}$ & $\frac{\infty}{\sigma}$ & 1 & $\stackrel{\circ}{\wedge}$ \\
\hline$\underline{s}$ & 1 & $\hat{i}$ & 1 & 1 & 1 & $\hat{i}$ & 1 & 1 & 1 & 1 & 1 & $\stackrel{\infty}{-}$ & 1 & 1 \\
\hline 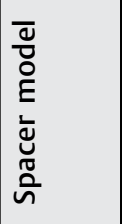 & 1 & 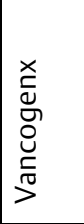 & 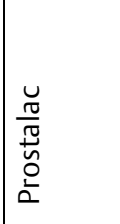 & 1 & 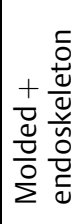 & 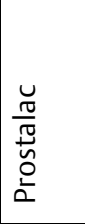 & 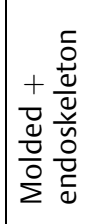 & 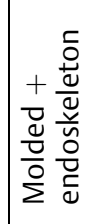 & \begin{tabular}{|l|} 
\\
$u$ \\
$\vdots$ \\
$\bar{u}$ \\
$\tilde{0}$ \\
$\tilde{n}$ \\
$n$
\end{tabular} & 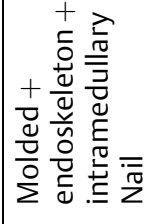 & 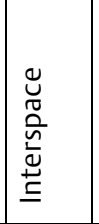 & 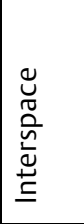 & 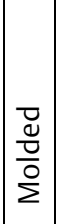 & $\begin{array}{l}\frac{u}{0} \\
\frac{\pi}{\tilde{N}} \\
\text { on } \\
\text { a }\end{array}$ \\
\hline 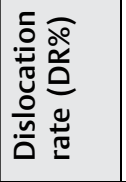 & 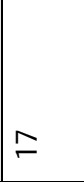 & $\stackrel{\sim}{\check{\sim}}$ & 1 & 1 & $a$ & 1 & 1 & 1 & $\begin{array}{l}\bar{\infty} \\
0 \\
0 \\
0\end{array}$ & & $\stackrel{\bullet}{\oplus}$ & 0 & $\circ$ & I \\
\hline 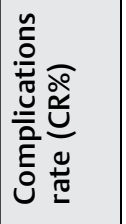 & શ & 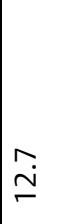 & 1 & 1 & $\ddot{\sim}$ & 1 & 1 & 1 & $\begin{array}{l}\bar{\infty} \\
\dot{0} \\
\ulcorner\end{array}$ & $a$ & 㐫 & 0 & $\circ$ & I \\
\hline 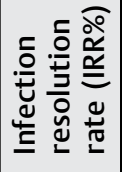 & ळ & $\bar{\sigma}$ & $\infty$ & $\begin{array}{l}\text { nn } \\
\text { ñ }\end{array}$ & $\infty$ & 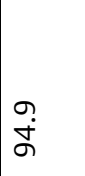 & $\frac{1}{\infty}$ & $\stackrel{R}{\curvearrowright}$ & $\bar{\sigma}$ & б & ஜ் & นn & ○ & ৪ \\
\hline 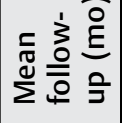 & ஜ & $\stackrel{\sim}{\sim}$ & $\stackrel{ \pm}{\sim}$ & $\stackrel{\sim}{\simeq}$ & $\mid \begin{array}{l}\infty \\
\dot{f}\end{array}$ & $\begin{array}{l}\infty \\
\infty \\
\infty\end{array}$ & $\begin{array}{l}\sim \\
\ddot{b} \\
\text { மn }\end{array}$ & ᄂn & $\frac{\infty}{\dot{n}}$ & $\simeq$ & $\stackrel{\Xi}{\sim}$ & 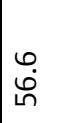 & $\simeq$ & f \\
\hline 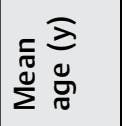 & $\hat{\sigma}$ & $\widetilde{\sigma}$ & $\mid \begin{array}{l}\infty \\
\stackrel{0}{R}\end{array}$ & 1 & ڤે̀ & $\frac{\hat{\sigma}}{\hat{\sigma}}$ & $\begin{array}{l}0 \\
\dot{\sigma}\end{array}$ & \begin{tabular}{|l} 
Ln \\
$\ddot{\theta}$ \\
0
\end{tabular} & 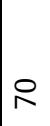 & 9 & $\begin{array}{l}m \\
\dot{\theta}\end{array}$ & 会 & 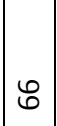 & ڤn \\
\hline$z$ & ๑ & F & શิ & $\frac{e^{0}}{\pi}$ & $\approx$ & $\stackrel{\sim}{\sim}$ & $\stackrel{\infty}{\stackrel{\infty}{\sim}}$ & $\stackrel{0}{\sim}$ & $\stackrel{\nabla}{\curvearrowright}$ & $\mp$ & $\stackrel{m}{\infty}$ & $\stackrel{\curvearrowright}{\sim}$ & $\circ$ & $\bar{m}$ \\
\hline 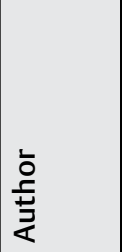 & 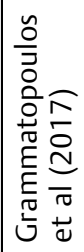 & 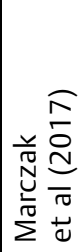 & 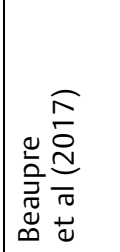 & 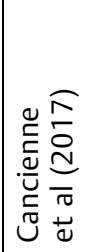 & 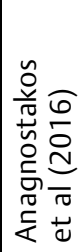 & 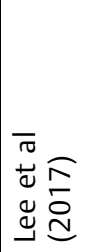 & 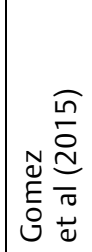 & 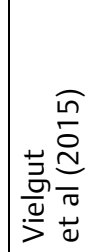 & 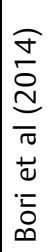 & 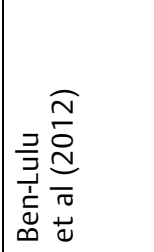 & 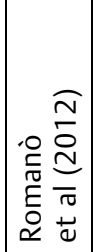 & 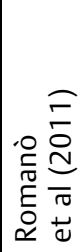 & 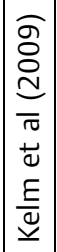 & 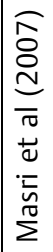 \\
\hline
\end{tabular}


Infection resolution rates results are quite satisfactory reaching approximately $90 \%$ but the procedure is not out of risks, in fact instability rates averaged around 8 to $10 \%$.

Information collected were (whenever reported) the type of implanted spacers, their functional result, the Girdlestone procedure rate, and the time of retention of the spacer. The average retention time of a spacer is approximately 5 months, though there are studies that reported a shorter time. ${ }^{25}$

Results obtained from literature are more than flattering and pave the path for a more aggressive treatment of PJI following THA. Patients who undergo surgery are by definition fragile patients.

Cancienne et al ${ }^{48}$ reported that $60 \%$ of the patients treated for PJI go through second stage while $16.8 \%$ retained the spacer.

Similar data are reported by Gomez et $\mathrm{al}^{16}$ : in this study 87 patients of 178 did not receive prosthesis reimplantation: $6.9 \%$ were amputated, $5.7 \%$ received resection arthroplasty according to Girdlestone, $4.6 \%$ were subjected to arthrodesis, and $82.8 \%$ maintained the spacer. The authors point out that in reality the success rate is less than $90 \%$ since many patients died between first and second stage. Obviously, a higher rate of success of the spacer retaining increases the rate of complications. ${ }^{16,54,55}$ Starting from the studies already mentioned in $\boldsymbol{- T a b l e} \mathbf{2}$ and integrating them with others present in literature we summarized the rates of the most common complications in - Table 3. ${ }^{12,14,17,18,45,47,50,55}$

It has to be noticed that the rate of complications is definitely higher for Petis et $\mathrm{al}^{55}$ than for the other studies that we compared. This can be attributed to the fact that in this study exclusively prolonged retention spacers were considered. Except for this study it can be highlighted that the complication rate fluctuates between 10 and $20 \%$.

Dislocation is the most frequent complication found in literature: its incidence is $8.46 \%$ in all 567 included patients. These results reflect those reported by Faschingbauer et al. ${ }^{45}$

In literature, very heterogeneous rates ranging from 10 to over $40 \%$ are reported..$^{25,56-58}$ Unlike Koo et al, Takahira et al and Shin et al ${ }^{41,59,60}$ did not observe any dislocation following the implantation of standardized spacers.

There are many variables that come into play in the case of dislocation: first of all, the type of spacers (handmade, molded, or prefabricated) and its geometry, the head/neck ratio, femoral fixation type, mismatch between spacer head and acetabular diameter, hypotrophy of surrounding muscles, previous surgical interventions and type of surgical approach, poor bone quality, patient compliance, education and maintenance of the physiotherapeutic path.

The first authors trying to identify the main risk factors were Leunig et al. ${ }^{57}$ Their study shows that the neck to head ratio was significantly higher in dislocating spacers $(0.96 \pm 0.19)$ than in those not-dislocating spacers $(0.76 \pm 0.05)$.

Another factor that can be associated with failure was an insufficient deep anchorage in the intramedullary canal; in fact, the complication-free spacers were on average deepened in femoral canal for $57 \pm 41 \mathrm{~mm}$, while the failure groups were deepened for only $22 \pm 33 \mathrm{~mm}$.

Spacer's fractures are the second complication by the incidence rate. From the data, we analyzed they occur in

\begin{tabular}{|c|c|c|c|c|c|c|c|c|c|}
\hline 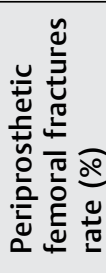 & 0 & 0 & 0 & 0 & 0 & $\stackrel{m}{m}$ & 0 & 0 & 0 \\
\hline 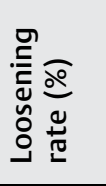 & f & 0 & 0 & 0 & 0 & 0 & $a$ & 0 & 0 \\
\hline 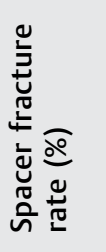 & $\begin{array}{l}\stackrel{0}{\stackrel{2}{r}} \\
=\end{array}$ & 0 & 0 & $\hat{m}$ & 0 & $\widehat{\infty}$ & 0 & 0 & 0 \\
\hline 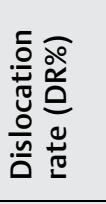 & $\stackrel{\infty}{\stackrel{\infty}{\nu}}$ & $\approx$ & $\frac{\tilde{v}}{\grave{i}}$ & $a$ & $\mid$\begin{tabular}{l}
$\infty$ \\
0 \\
\hdashline
\end{tabular} & $\stackrel{r}{\infty}$ & a & $\begin{array}{l}\dot{\vartheta} \\
\dot{\varphi}\end{array}$ & $\stackrel{\circ}{-}$ \\
\hline 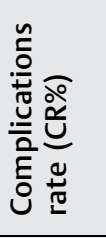 & $\begin{array}{c}\sim \\
\infty \\
\infty\end{array}$ & ని & 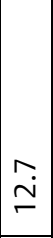 & $\ddot{\sim}$ & $\mid$\begin{tabular}{l}
$\infty$ \\
$\infty$ \\
\hdashline
\end{tabular} & $\begin{array}{l}\sigma \\
\dot{0} \\
\sigma\end{array}$ & $a$ & 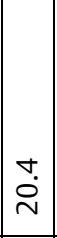 & $\stackrel{\circ}{\circ}$ \\
\hline 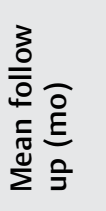 & $\stackrel{d}{\sim}$ & ด̆ & $\stackrel{\searrow}{\sim}$ & $\begin{array}{l}\infty \\
\dot{f}\end{array}$ & 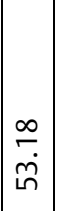 & $m$ & $\simeq$ & $\stackrel{ \pm}{\sim}$ & $\stackrel{\sim}{\sim}$ \\
\hline 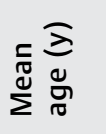 & $\stackrel{\substack{\infty \\
\infty}}{\stackrel{\infty}{\sim}}$ & 6 & $\widetilde{\sigma}$ & مَ' & 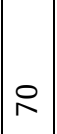 & $\begin{array}{c}m \\
\dot{\theta}\end{array}$ & I & $\begin{array}{l}m \\
\dot{0} \\
\dot{\theta}\end{array}$ & $\mathscr{8}$ \\
\hline$z$ & 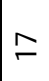 & เి & F & $\approx$ & 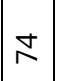 & $\stackrel{\infty}{m}$ & $=$ & $\begin{array}{l}\infty \\
\infty \\
-\end{array}$ & $\stackrel{\circ}{\div}$ \\
\hline & 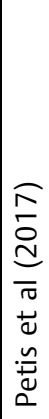 & 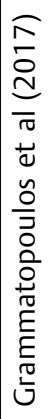 & 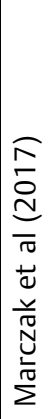 & 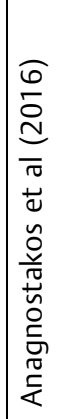 & 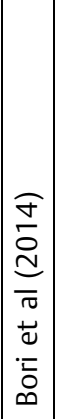 & 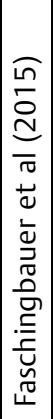 & 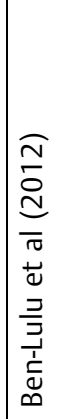 & 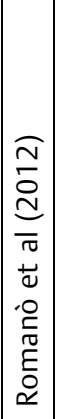 & 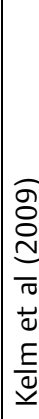 \\
\hline
\end{tabular}


approximately $10 \%$ of the cases, ranging in literature from 10 to $15 \%{ }^{25,61}$ For preventing spacer's fractures some studies suggest the reinforcement with Steinmann's pins, intramedullary nails, or prostheses.

Kummer et $\mathrm{al}^{62}$ reported as spacers with prostheses and the commercial spacers did not fail at 3,000 N while those reinforced with pins failed at $832 \mathrm{~N}$ and those with nails at $1,275 \mathrm{~N}$. Thielen et $\mathrm{al}^{63}$ studied in vitro the mechanical stability of spacers reinforced with endoskeleton compared with nonreinforced spacers. Nonreinforced spacers failed at 400 to $600 \mathrm{~N}$ while rod-reinforced spacers failed at 1,000 to $1,300 \mathrm{~N}$. "Full-stem" reinforced spacers failed at different forces that ranged from 2,380 to $4,311 \mathrm{~N}$ depending on the thickness of endoskeleton. For Jung et $\mathrm{al}^{25}$ there are no clinical data for demonstrating that metallic endoskeleton improves the mechanical properties, unlike what is sanctioned by Faschingbauer et al. ${ }^{45}$ Moreover, Jung et $\mathrm{al}^{25}$ underlined the fact that it is still unclear whether the use of endoskeleton has adverse effects on the pharmacokinetic properties of the spacer.

We do not have to forget the risk of periprosthetic fractures, facilitated by concomitant osteoporosis and poor bone-stock derived from infection and previous implant removal and debridement procedures.

\section{Conclusion}

Treatment of chronic hip joint infections after THA is a challenging problem. Two-stage revision arthroplasty with the use of antibiotic-loaded spacers is the gold standard and permits an infection rate control over $90 \%$.

The use of spacers provides a lot of advantages like maintaining limb length, joint mobility, and partial weight bearing.

The major complications are dislocation and spacer's rupture. Actually, the best antibiotic and mixing association (antibiotic and dose) is still debated.

A multimodal approach is necessary to increase success rate in treating these cases. A team composed by orthopedic surgeon, physical therapist, and infectious disease specialist must be created to take advantage of their combined skills and to ensure the best possible treatment to the patient.

\section{Conflict of Interest}

None declared.

\section{References}

1 Zimmerli W, Trampuz A, Ochsner PE. Prosthetic-joint infections. N Engl J Med 2004;351(16):1645-1654

2 Haaker R, Senge A, Krämer J, Rubenthaler F. [Osteomyelitis after endoprostheses]. Orthopade 2004;33(04):431-438

3 Kurtz SM, Lau E, Watson H, Schmier JK, Parvizi J. Economic burden of periprosthetic joint infection in the United States. JArthroplasty 2012;27(8, Suppl):61-65

4 Chen SY, Hu CC, Chen CC, Chang YH, Hsieh PH. Two-stage revision arthroplasty for periprosthetic hip infection: mean follow-up of ten years. BioMed Res Int 2015;2015:345475

5 Parvizi J, Zmistowski B, Berbari EF, et al. New definition for periprosthetic joint infection: from the Workgroup of the Musculoskeletal Infection Society. Clin Orthop Relat Res 2011;469 (11):2992-2994
6 Parvizi J, Adeli B, Zmistowski B, Restrepo C, Greenwald AS. Management of periprosthetic joint infection: the current knowledge: AAOS exhibit selection. J Bone Joint Surg Am 2012;94(14):e104

7 Illingworth KD, Mihalko WM, Parvizi J, et al. How to minimize infection and thereby maximize patient outcomes in total joint arthroplasty: a multicenter approach: AAOS exhibit selection. J Bone Joint Surg Am 2013;95(08):e50

8 Donlan RM, Costerton JW. Biofilms: survival mechanisms of clinically relevant microorganisms. Clin Microbiol Rev 2002;15 (02):167-193

9 del Pozo JL, Patel R. The challenge of treating biofilm-associated bacterial infections. Clin Pharmacol Ther 2007;82(02):204-209

10 Harris LG, El-Bouri K, Johnston S, et al. Rapid identification of staphylococci from prosthetic joint infections using MALDI-TOF mass-spectrometry. Int J Artif Organs 2010;33(09):568-574

11 Grammatopoulos G, Bolduc ME, Atkins BL, et al. Functional outcome of debridement, antibiotics and implant retention in periprosthetic joint infection involving the hip: a case-control study. Bone Joint J 2017;99-B(05):614-622

12 Marczak D, Synder M, Sibiński M, Polguj M, Dudka J, Kowalczewski J. Two stage revision hip arthroplasty in periprosthetic joint infection. Comparison study: with or without the use of a spacer. Int Orthop 2017;41(11):2253-2258

13 Beaupre LA, Stampe K, Masson E, et al. Health-related quality of life with long-term retention of the PROSthesis of antibiotic loaded acrylic cement system following infection resolution in low demand patients. JOrthop Surg (Hong Kong) 2017;25(02): 2309499017716257

14 Anagnostakos K, Duchow L, Koch K. Two-stage protocol and spacer implantation in the treatment of destructive septic arthritis of the hip joint. Arch Orthop Trauma Surg 2016;136(07):899-906

15 Lee WY, Hwang DS, Kang C, Shin BK, Zheng L. Usefulness of prosthesis made of antibiotic-loaded acrylic cement as an alternative implant in older patients with medical problems and periprosthetic hip infections: a 2- to 10-year follow-up study. J Arthroplasty 2017;32(01):228-233

16 Gomez MM, Tan TL, Manrique J, Deirmengian GK, Parvizi J. The fate of spacers in the treatment of periprosthetic joint infection. J Bone Joint Surg Am 2015;97(18):1495-1502

17 Ben-Lulu O, Farno A, Gross AE, Backstein DJ, Kosashvili Y, Safir OA. A modified cement spacer technique for infected total hip arthroplasties with significant bone loss. J Arthroplasty 2012;27(04):613-619

18 Romanò CL, Romanò D, Albisetti A, Meani E. Preformed antibioticloaded cement spacers for two-stage revision of infected total hip arthroplasty. Long-term results. Hip Int 2012;22(Suppl 8):S46-S53

19 Tande AJ, Patel R. Prosthetic joint infection. Clin Microbiol Rev 2014;27(02):302-345

20 Akgün D, Trampuz A, Perka C, Renz N. High failure rates in treatment of streptococcal periprosthetic joint infection: results from a seven-year retrospective cohort study. Bone Joint J 2017; 99-B(05):653-659

21 Kini SG, Gabr A, Das R, Sukeik M, Haddad FS. Two-stage revision for periprosthetic hip and knee joint infections. Open Orthop J 2016;10(Suppl 2):579-588

22 Younger TI, Bradford MS, Magnus RE, Paprosky WG. Extended proximal femoral osteotomy. A new technique for femoral revision arthroplasty. J Arthroplasty 1995;10(03):329-338

23 Charity J, Tsiridis E, Gusmão D, Bauze A, Timperley J, Gie G. Extended trochanteric osteotomy followed by cemented impaction allografting in revision hip arthroplasty. J Arthroplasty 2013; 28(01):154-160

24 Chen KH, Tsai SW, Wu PK, Chen CF, Wang HY, Chen WM. Partial component-retained two-stage reconstruction for chronic infection after uncemented total hip arthroplasty: results of sixteen cases after five years of follow-up. Int Orthop 2017;41(12):2479-2486

25 Jung J, Schmid NV, Kelm J, Schmitt E, Anagnostakos K. Complications after spacer implantation in the treatment of hip joint infections. Int J Med Sci 2009;6(05):265-273 
26 Anagnostakos K, Kelm J. Enhancement of antibiotic elution from acrylic bone cement. J Biomed Mater Res B Appl Biomater 2009;90 (01):467-475

27 Gálvez-López R, Peña-Monje A, Antelo-Lorenzo R, et al. Elution kinetics, antimicrobial activity, and mechanical properties of 11 different antibiotic loaded acrylic bone cement. Diagn Microbiol Infect Dis 2014;78(01):70-74

28 Jiranek WA, Hanssen AD, Greenwald AS. Antibiotic-loaded bone cement for infection prophylaxis in total joint replacement. J Bone Joint Surg Am 2006;88(11):2487-2500

29 Moran JM, Greenwald AS, Matejczyk MB. Effect of gentamicin on shear and interface strengths of bone cement. Clin Orthop Relat Res 1979;(141):96-101

30 Seldes RM, Winiarsky R, Jordan LC, et al. Liquid gentamicin in bone cement: a laboratory study of a potentially more cost-effective cement spacer. J Bone Joint Surg Am 2005;87(02):268-272

31 Lewis G, Janna S, Bhattaram A. Influence of the method of blending an antibiotic powder with an acrylic bone cement powder on physical, mechanical, and thermal properties of the cured cement. Biomaterials 2005;26(20):4317-4325

32 Dunne NJ, Hill J, McAfee P, Kirkpatrick R, Patrick S, Tunney M. Incorporation of large amounts of gentamicin sulphate into acrylic bone cement: effect on handling and mechanical properties, antibiotic release, and biofilm formation. Proc Inst Mech Eng H 2008; 222(03):355-365

33 McLaren AC, Nugent M, Economopoulos K, Kaul H, Vernon BL, McLemore R. Hand-mixed and premixed antibiotic-loaded bone cement have similar homogeneity. Clin Orthop Relat Res 2009;467 (07):1693-1698

34 DeLuise M, Scott CP. Addition of hand-blended generic tobramycin in bone cement: effect on mechanical strength. Orthopedics 2004;27(12):1289-1291

35 Masri BA, Duncan CP, Beauchamp CP. Long-term elution of antibiotics from bone-cement: an in vivo study using the prosthesis of antibiotic-loaded acrylic cement (PROSTALAC) system. JArthroplasty 1998;13(03):331-338

36 Hsieh PH, Chang YH, Chen SH, Ueng SW, Shih CH. High concentration and bioactivity of vancomycin and aztreonam eluted from Simplex cement spacers in two-stage revision of infected hip implants: a study of 46 patients at an average follow-up of 107 days. J Orthop Res 2006;24(08):1615-1621

37 Anagnostakos K, Wilmes P, Schmitt E, Kelm J. Elution of gentamicin and vancomycin from polymethylmethacrylate beads and hip spacers in vivo. Acta Orthop 2009;80(02):193-197

38 Boelch SP, Jordan MC, Arnholdt J, Rudert M, Luedemann M, Steinert AF. Loading with vancomycin does not decrease gentamicin elution in gentamicin premixed bone cement. J Mater Sci Mater Med 2017; 28(07):104

39 Anagnostakos K, Meyer C. Antibiotic elution from hip and knee acrylic bone cement spacers: a systematic review. BioMed Res Int 2017;2017:4657874

40 Citak M, Argenson JN, Masri B, et al. Spacers. J Orthop Res 2014;32 (Suppl 1):S120-S129

$41 \mathrm{Koo} \mathrm{KH}$, Yang JW, Cho SH, et al. Impregnation of vancomycin, gentamicin, and cefotaxime in a cement spacer for two-stage cementless reconstruction in infected total hip arthroplasty. J Arthroplasty 2001;16(07):882-892

42 van Raaij TM, Visser LE, Vulto AG, Verhaar JA. Acute renal failure after local gentamicin treatment in an infected total knee arthroplasty. J Arthroplasty 2002;17(07):948-950

43 Patrick BN, Rivey MP, Allington DR. Acute renal failure associated with vancomycin- and tobramycin-laden cement in total hip arthroplasty. Ann Pharmacother 2006;40(11):2037-2042

44 Wentworth SJ, Masri BA, Duncan CP, Southworth CB. Hip prosthesis of antibiotic-loaded acrylic cement for the treatment of infections following total hip arthroplasty. J Bone Joint Surg Am 2002;84-A(Suppl 2):123-128
45 Faschingbauer M, Reichel H, Bieger R, Kappe T. Mechanical complications with one hundred and thirty eight (antibiotic-laden) cement spacers in the treatment of periprosthetic infection after total hip arthroplasty. Int Orthop 2015;39(05):989-994

46 Sukeik M, Haddad FS. Two-stage procedure in the treatment of late chronic hip infections-spacer implantation. Int J Med Sci 2009;6(05):253-257

47 Grammatopoulos G, Bolduc ME, Atkins BL, et al. Functional outcome of debridement, antibiotics and implant retention in periprosthetic joint infection involving the hip: a case-control study. Bone Joint J 2017;99-B(05):614-622

48 Cancienne JM, Werner BC, Bolarinwa SA, Browne JA. Removal of an infected total hip arthroplasty: risk factors for repeat debridement, long-term spacer retention, and mortality. J Arthroplasty 2017;32(08):2519-2522

49 Vielgut I, Sadoghi P, Wolf M, et al. Two-stage revision of prosthetic hip joint infections using antibiotic-loaded cement spacers: when is the best time to perform the second stage? Int Orthop 2015;39(09): 1731-1736

50 Bori G, García-Oltra E, Soriano A, Rios J, Gallart X, Garcia S. Dislocation of preformed antibiotic-loaded cement spacers (Spacer-G): etiological factors and clinical prognosis. JArthroplasty 2014;29(05):883-888

51 Romanò CL, Romanò D, Meani E, Logoluso N, Drago L. Two-stage revision surgery with preformed spacers and cementless implants for septic hip arthritis: a prospective, non-randomized cohort study. BMC Infect Dis 2011;11:129

52 Kelm J, Bohrer P, Schmitt E, Anagnostakos K. Treatment of proximal femur infections with antibiotic-loaded cement spacers. Int J Med Sci 2009;6(05):258-264

53 Masri BA, Panagiotopoulos KP, Greidanus NV, Garbuz DS, Duncan $\mathrm{CP}$. Cementless two-stage exchange arthroplasty for infection after total hip arthroplasty. JArthroplasty 2007;22(01): 72-78

54 Kahlenberg CA, Hernandez-Soria A, Cross MB. Poor prognosis of patients treated for periprosthetic joint infection. HSS J 2017;13 (01):96-99

55 Petis SM, Perry KI, Pagnano MW, Berry DJ, Hanssen AD, Abdel MP. Retained antibiotic spacers after total hip and knee arthroplasty resections: high complication rates. J Arthroplasty 2017;32(11): 3510-3518

56 Magnan B, Regis D, Biscaglia R, Bartolozzi P. Preformed acrylic bone cement spacer loaded with antibiotics: use of two-stage procedure in 10 patients because of infected hips after total replacement. Acta Orthop Scand 2001;72(06):591-594

57 Leunig M, Chosa E, Speck M, Ganz R. A cement spacer for twostage revision of infected implants of the hip joint. Int Orthop 1998;22(04):209-214

58 Duncan CP, Beauchamp C. A temporary antibiotic-loaded joint replacement system for management of complex infections involving the hip. Orthop Clin North Am 1993;24(04):751-759

59 Takahira N, Itoman M, Higashi K, Uchiyama K, Miyabe M, Naruse K. Treatment outcome of two-stage revision total hip arthroplasty for infected hip arthroplasty using antibiotic-impregnated cement spacer. J Orthop Sci 2003;8(01):26-31

60 Shin SS, Della Valle CJ, Ong BC, Meere PA. A simple method for construction of an articulating antibiotic-loaded cement spacer. J Arthroplasty 2002;17(06):785-787

61 Diamond OJ, Masri BA. Articulating antibiotic impregnated spacers in prosthetic joint infections: where do we stand? Int J Surg 2018;54(Pt B):345-350

62 Kummer FJ, Strauss E, Wright K, Kubiak EN, Di Cesare PE. Mechanical evaluation of unipolar hip spacer constructs. Am J Orthop 2008;37(10):517-518

63 Thielen T, Maas S, Zuerbes A, Waldmann D, Anagnostakos K, Kelm J. Development of a reinforced PMMA-based hip spacer adapted to patients' needs. Med Eng Phys 2009;31(08):930-936 